\title{
BIBLIOTECAS Y POLÍTICA: EL PARADIGMA POLÍTICO DE LA BIBLIOTECA PÚBLICA
}

\author{
Felipe Meneses Tello* \\ Facultad de Filosofía y Letras. Universidad Nacional Autónoma de México.
}

\begin{abstract}
Resumen: El autor analiza algunos aspectos en torno a la dimensión política de la biblioteca pública. Así, afirma que la relación de la política con la disciplina de la bibliotecología y la práctica de la biblioteconomía es un tópico complejo que puede ser analizado desde diferentes enfoques. El trata el mito apolítico de la biblioteca pública a través de la discusión de cuatro factores políticos acerca de esta institución bibliotecaria: el gubernamental, el ciudadano, el electoral y el revolucionario.

Palabras clave: Biblioteca pública; bibliotecas y política; bibliotecología y política; biblioteconomía y política.
\end{abstract}

Title: LIBRARIES AND POLITICS: THE POLITICAL PARADIGM OF THE PUBLIC LIBRARY.

Abstract: The author analyzes some aspects around the political dimension of the public library. In this way, he states that the connection of politics with the discipline of library science and the practice of librarianship is a complex topic which can be analyzed from different approaches. He deals with the apolitical myth of the public library through the discussion of four political factors about libraries: government, citizens, electoral and revolutionary.

Keywords: Public library; libraries and politics; library science and politics; librarianship and politics.

\section{INTRODUCCIÓN: ENFOQUES Y CATEGORÍAS ENTRE BIBLIOTECAS Y POLÍTICA.}

Si la relación básica de «bibliotecas y sociedad» corresponde en esencia al paradigma social de la biblioteca pública, la conexión «bibliotecas y Estado» concierne en sustancia al paradigma político de este tipo de centro bibliotecario. El paradigma social de este tipo de centro bibliotecario se vincula con lo que expresamos como «bibliotecología social»; el paradigma político responde a lo que podemos denominar apropiadamente como «bibliotecología política».

Ciertamente ambos vínculos no se limitan a la biblioteca pública, pero acorde con la naturaleza de este servicio público es posible percibir de manera más explícita la compleja dimensión política que se distingue en torno a las funciones que desempeña como institución social en el entramado del Estado.

La palabra «política» significa la actividad que tiene como objetivo gobernar la acción del Estado en provecho de la sociedad. Es, asimismo, procedimiento orientado ideológicamente hacia la toma de decisiones para alcanzar los objetivos de los diversos grupos sociales en materia de asuntos públicos. La política como forma de praxis humana está relacionada con el poder político entre gobernantes y gobernados (Bobbio, 1997, p. 1215). Categorías que constituyen el elemento humano de la organización política conocida como Estado.

Los primeros constituyen la ciudadanía gobernante, quien desempeña la función de alta dirección del Estado, por ende, es quien encarna el poder político estatal. Mientras que los segundos conforman la ciudadanía gobernada, esto es, el pueblo en términos generales. El pueblo, elemento esencial del Estado, es dotado de varios tipos de bibliotecas para el desarrollo de sus tareas que le corresponde realizar en beneficio propio y de la colectividad, de la sociedad y del Estado. El bibliotecólogo social, basándose principalmente en la teoría liberal del Estado, contempla como una función rectora de esta institución de instituciones la satisfacción de las necesidades sociales de los ciudadanos a través de una serie de servicios públicos, entre los que percibe el servicio de biblioteca pública, destinado para asistir a la generalidad de los gobernados, es decir, a los diferentes grupos y clases sociales que constituyen el pueblo. Por tal motivo, este tipo de biblioteca es la base de la pirámide social del sistema bibliotecario nacional del Estado.

La conexión de la política con la disciplina de la bibliotecología y la práctica de la biblioteconomía es un tópico general que ha sido analizado desde diferentes puntos de vista. Estos enfoques los podemos sintetizar mediante los siguientes vínculos:

- «política y bibliotecología» (Birdsall, 1988a; Blanke, 1989; Meneses, 2007; Smith, 2009)

*fmeneses@unam.mx

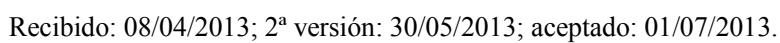

MENESES TELLO, F. Bibliotecas y política: el paradigma político de la biblioteca pública. Anales de Documentación, 2013 , vol. 16, $\mathrm{n}^{\circ}$ 2. Disponible en: http://dx.doi.org/10.6018/analesdoc.16.2.172471 
- «política y bibliotecas» (Dosa, 1974; Martin, W. 1974/1975; Lick, 1984; Meneses, 1994; Meneses, 2007; Smith, 2009)

- «política y bibliotecología pública» (Bergen, 1985; Shavit, 1986; Burton, 2009)

- «política y bibliotecas públicas» (Berelson, 1945; Garceau, 1949; O’Kelly, 1977; Birdsall, 1988b; Carrigan, 1989; White, 1989; Usherwood, 1991, 1993, 1994, 1996; García y Sutherland, 2001; Meneses, 2008)

El prototipo político de la biblioteca pública comprende en la literatura especialmente las dos últimas relaciones.

En concordancia con la literatura publicada sobre el tema, observamos que la apreciación de la biblioteca pública en la esfera de la política no es reciente. El libro de Oliver Garceau, publicado a mediados del siglo XX bajo el título The public library in the political process es una clara evidencia. Obra en la que se transmite el potencial politico de la biblioteca pública, pues es de suma importancia "para los bibliotecarios, para el servicio de biblioteca y para los ciudadanos que los bibliotecarios públicos comprendan y aprecien más claramente el mundo político de la biblioteca pública" (Garceau, 1949, p. 239). De acuerdo con este punto de vista y como se argumenta más adelante, esta institución bibliotecaria no está al margen de la política, pues la política no es ajena al desarrollo y a la consolidación de esta institución de lectura pública en el seno de la sociedad. La literatura en torno a la biblioteca pública muestra claros indicios en este sentido.

\section{EL MITO APOLÍTICO DE LA BIBLIOTECA PÚBLICA.}

En esta esfera "las bibliotecas y la política son inseparables... las bibliotecas siempre han sido un proyecto político" (Vitzansky, 2009, p. 117). Desde esta óptica, la ciencia política es considerada útil para investigar el funcionamiento del objeto institucional de estudio de la bibliotecología en general y de la bibliotecología pública en particular para así orientar nuestra disciplina hacia la búsqueda de nuevos conocimientos (Robbins-Carter, 1984, p. 435). Pese a este enfoque interdisciplinario, "muchos bibliotecarios de bibliotecas públicas han llegado a creer el mito apolítico de la biblioteca pública" (Shavit, 1986, p. 4), por ende, algunos bibliotecarios han continuado intentando perpetuar el mito de que la bibliotecología es apolítica (Birdsall, 1988a, p. 75), es decir, neutra o indiferente a la política o que se abstiene de intervenir en esta esfera. En relación con este problema Birdsall, en otro de sus artículos, afirma:

Los bibliotecarios suelen evitar delinear explícitamente los fundamentos ideológicos subyacentes a las metas y programas institucionales. Mejor promueven a la biblioteca como una institución neutral libre de sesgos ideológicos. Sin embargo, podríamos contribuir a una mejor comprensión del desarrollo de la biblioteca pública si intentamos resolver temas políticos dominantes que constituyen el tejido de la ideología respecto a la biblioteca pública (1988b, p. 57).

En contraste, a través de la formulación de este modelo se intenta observar a la biblioteca pública como una «institución política». Este propósito quizás produzca asombro en unos e incredulidad en otros, particularmente entre aquellos colegas que han seguido el credo ortodoxo de la separación, teórica y práctica, de la política con respecto al ejercicio que implica organización y administración de instituciones bibliotecarias públicas, particularmente aquellas dirigidas a toda la población.

También ha sido un mito pensar que la práctica en general de esta disciplina (la biblioteconomía pública) es apolítica, cuya tradición la observamos a través del discurso técnico gerencial tan socorrido en la literatura especializada, mismo que ha venido defendiendo el principio de la neutralidad ante problemas que demandan compromiso social (López, 2008, p. 65) por parte de quienes hacen funcionar esta institución de servicio público. Punto de vista que coincide con quien desde hace tiempo afirmaría que "la bibliotecología y las ciencias de la información no son neutrales" porque las técnicas bibliotecarias no son "independientes de los fines culturales, sociales y políticos de cada modelo de sociedad” (Depallens, 1987, p. 8). Así, afirmar que la bibliotecología y/o biblioteconomía pública en particular nada tiene de relación con la política, es un error de abstracción posible y pertinente de corregir. En efecto, como se asevera a continuación:

La bibliotecología pública ha venido funcionando bajo el mito de que las bibliotecas públicas no son instituciones políticas. El mito de que las bibliotecas públicas deben mantenerse fuera de la política y la política de las bibliotecas públicas ha tenido una tradición de larga data. (Shavit, 1986, p. 1).

La biblioteca pública, que fue anunciada como un instrumento de la democracia, ha rechazado, en general, el mundo político en el que operan las instituciones democráticas y ha insistido en la independencia de cualquier otra agencia o instrumento de los gobiernos locales. Sin embargo, dado que las decisiones políticas afectan a 
los programas de bibliotecas públicas, la bibliotecología pública es, evidentemente, política. (Shavit, 1986, p. $3)$.

En consonancia con esta percepción, este mismo autor asevera sin la menor duda que "las bibliotecas públicas son instituciones políticas y parte del sistema político" (Shavit, 1986, p. 4). De modo que el enfoque referente a «la biblioteca pública como institución social» se convierte en el concerniente a «la biblioteca pública como institución política». Punto de vista con el que concordamos porque estas instituciones: 1] se sostienen con presupuesto público, 2] este presupuesto procede de la hacienda pública o de la recaudación fiscal que mantiene la ciudadanía, 3] forman parte de la estructura pública gubernamental y 4] constituyen parte del proceso político al ser afectadas por éste en su gestión y financiación (García y Sutherland, 2001, p. 13). Este encuadre «político» es en el sentido del término que concierne a la administración del Estado.

Esta perspectiva sugiere pensar que las bibliotecas públicas son instituciones políticas porque se hallan en la arena política de la Administración Pública del Estado. Es decir, forman parte tanto de la 1] política cultural como de la 2] cultura política en el entramado de esta máxima entidad de gobierno. La variedad de fuentes, provenientes de las diversas formaciones sociales (conservadurismo, liberalismo y socialismo) en relación con la ideología de la biblioteca pública es lo que configura la relación dialéctica entre cultura y política (Birdsall, 1988b, p. 55). En este sentido, la biblioteca pública se configura como una institución cultural en la esfera práctica de la política. La relación entre «bibliotecas públicas y política» proyecta así tanto el nivel de conocimiento y uso del servicio de biblioteca pública por parte del pueblo (cultura bibliotecaria) como el resultado de las actividades gubernamentales para crear, desarrollar y consolidar este servicio como componente de los servicios públicos que debe ofrecer el Estado a los diversos grupos sociales que conforman el pueblo (política bibliotecaria).

Así, el servicio de biblioteca pública es parte de los servicios públicos que apuntan a satisfacer las necesidades colectivas e individuales de información, educación y recreación de quienes habitan el Estado en sus tres dimensiones geopolíticas de órdenes de gobierno: la federal, la estatal y la municipal o local. En este orden de ideas, «la biblioteca pública como institución política» se encuentra inmersa en la esfera de lo público. En razón de esto, «la biblioteca pública como institución pública» no es una simple formulación tautológica, es una reafirmación correspondiente a su ejercicio en lo político dentro de la estructura política del Estado.

Si la bibliotecología pública y su objeto esencial de estudio (la biblioteca pública) no son ajenos al fenómeno de la política, entonces por extensión el bibliotecario público tampoco debería mantenerse desinteresado e indiferente a los procesos políticos que afectan su trabajo. Al respecto se reflexiona que este sujeto

No es apolítico, neutro, imparcial. ¿Cómo puede el bibliotecario considerarse imparcial si la propia localización de la biblioteca donde trabaja sirve a intereses políticos y que no expresan una real necesidad de la comunidad? ¿Cómo puede el bibliotecario considerarse imparcial si aquellos que más necesitan de la biblioteca están imposibilitados de hacer uso de ella?

Tenemos que llegar a la población necesitada, a la población carente de información. No será con esa actitud apática, pasiva y reaccionaria de la biblioteca de hoy que tenga éxito. No basta esparcir bibliotecas en cada cuadra, en cada esquina. Se necesita que el bibliotecario que actúa en esas bibliotecas sea otro bibliotecario; es preciso que él sea consciente de su real función social; es necesario que él sepa que su trabajo puede y debe cambiar pensamientos y comportamientos; se necesita que vaya a la población, que procure al pueblo, que trabaje con la comunidad. (Almeida, 1997, p. 92).

A través de estas visiones críticas, sobran argumentos sociales y políticos para refutar terminantemente el mito tradicional que nos ocupa en relación con la tríada: bibliotecología pública, biblioteca pública y bibliotecario público. Categorías que podemos configurar con toda propiedad en conceptos tales como: bibliotecología politica, biblioteca política y bibliotecario político, para así estudiar y analizar una serie de factores relacionados estrechamente con todos aquellos fenómenos inherentes al público y lo público, esto es, alusivos a la política y lo político desde diferentes enfoques. Esto nos permitirá explicar a los escépticos que el valor semántico del adjetivo "política" es esencial para entender tanto el objeto de estudio como la práctica objetiva del servicio de biblioteca pública como parte constitutiva para la acción del Estado en provecho de la sociedad.

Dado que se sigue poniendo en entredicho las posturas que manifiestan indiferencia o desinterés frente a la política en el marco de la historia bibliotecológica y la práctica bibliotecaria, la crítica continúa aún hoy en día respecto al mito aludido. La siguiente afirmación muestra un claro ejemplo en este sentido: 
La creación de la Biblioteca Pública [de Buenos Aires] fue un suceso político y revolucionario ${ }^{1}$, dos conceptos temidos y eludidos por los profesionales de hoy; pues hemos sido formados, en forma contraria a nuestros inicios, en una especie de asepsia política. A tal punto que la imagen de un buen bibliotecario es aquella que lo representa como apolítico y alejado de todo tipo de cambio revolucionario. (Parada, 2012, p. 171-172).

En efecto, si la palabra «política» produce peculiar resquemor en los diversos entornos del quehacer bibliotecario y del pensamiento bibliotecológico; el término «revolución»en estos mismos cuadrantes provoca si no pavor sí rechazo. Así, aún y cuando la historia de las bibliotecas públicas no puede sostenerse al margen del análisis de los relevantes procesos políticos, ciudadanos y revolucionarios, en las escuelas sobre nuestra disciplina se continúa cultivando, en aras principalmente de la enseñanza técnico-administrativa, el espíritu apolítico entre los estudiantes. En los institutos de investigación sucede lo mismo ya que en la esfera de la producción teórico-histórica acerca de los objetos y fenómenos de estudio y análisis de nuestra disciplina y profesión persiste aquella literatura hispanoamericana predominantemente ajena a esos procesos. Naturalmente que existen algunos escritos con puntos de vista que se apartan de lo anodino u ordinario, como los que nos permiten profundizar la negación del mito apolítico de la institución bibliotecaria en cuestión en los siguientes rubros.

\section{EL FACTOR POLÍTICO GUBERNAMENTAL DE LA BIBLIOTECA PÚBLICA.}

El factor gubernamental, entonces, es uno de los principales planteamientos en torno al nexo «bibliotecas públicas y proceso político» porque "los gobiernos federales, estatales y locales están involucrados en la formulación e implementación de las políticas de la biblioteca pública” (Shavit, 1986, p. 7), mismas que forman parte de la «política bibliotecaria» del Estado y que converge ésta entre la política cultural y la política de información (García, 2003, p. 25). Consecuentemente, estos centros bibliotecarios son:

- Objeto de políticas de equipamiento (construcción, remodelación o ampliación de los edificios de bibliotecas públicas al servicio de la comunidad)

- Materia de políticas de educación pública (visto este tipo de biblioteca como auxiliar del sistema de las escuelas públicas enclavadas en el nivel básico)

- Argumento de políticas de información (el servicio de biblioteca pública como institución garante para construir una ciudadanía informada)

- Asunto de políticas de recreación cultural (la biblioteca pública activa que permita el disfrute, libre, gratuito y sin discriminación alguna, de las distintas manifestaciones culturales para el pleno desarrollo de los presentes y futuros ciudadanos)

- Tema de políticas de bienestar social (prestación del servicio público de biblioteca con el fin de que los miembros de la comunidad logren una mejor calidad de vida)

En suma, el servicio de biblioteca pública debe ser un tópico importante de las políticas de gobierno y de estado. La percepción de que las bibliotecas están adheridas al mundo de la política se refuerza cuando observamos, por ejemplo, que estas instituciones se mencionan, aunque lacónicamente, en obras referentes al estudio del derecho de la política (Lescieur, 2000, p. 122) y derecho municipal (Andrade, 2006, p. 282). Y es así porque en el marco de los servicios públicos municipales encontramos el servicio de biblioteca pública. Servicios que están sujetos a normas de derecho público y que, como concepto, son parte central del derecho administrativo y, por tanto, pueden se parte del objeto de estudio del derecho municipal. En todo caso, las bibliotecas públicas pueden ser motivo también de la rama del derecho constitucional en tanto que ellas son mencionadas en las normas jurídico-políticas de lo que se nombra como la Ley suprema, esto es, la Constitución política. Norma jurídico-pública positiva del Estado y cuyo radio de acción alcanza todo lo público.

Un punto de vista elocuente y sugerente en torno a la estrecha relación política que existe entre «biblioteca pública y gobierno» nos permite entender mejor la dimensión institucional de este espacio bibliotecario:

La responsabilidad principal del gobierno es promover el orden público mediante el fortalecimiento de estas instituciones [sociales como la escuela, la familia y la biblioteca]. La biblioteca pública a menudo se promueve como uno de los baluartes institucionales de la comunidad aportando tanto su memoria social como una colaboración importante para el orden social. (Birdsall, 1988b, p. 57).

\footnotetext{
${ }^{1}$ Nota del editor: en el original de Parada el autor escribe en cursiva: ...suceso político y revolucionario. Aquí se escribe normal por usar la revista la letra cursiva en los párrafos de obras citadas.
} 
Pensar que las bibliotecas públicas son instituciones que apoyan el orden público o el orden social que gestiona el administrador esencial del Estado, es decir, el gobierno en turno, es pertinente considerar que ellas son, como las bibliotecas de otros tipos, fuentes simbólicas de poder que deriva principalmente del hecho de que estas instituciones "son el almacén de conocimientos y las depositarias de los registros de los logros y descubrimientos de la humanidad" (Thompson, 1974, p. 110).

Si bien más adelante se analiza el factor revolucionario de la biblioteca pública, el factor gubernamental de esta institución bibliotecaria en determinados acontecimientos históricos está estrechamente vinculado con los procesos denominados «revoluciones». Esta perspectiva entrelazada es posible ilustrarla con el antecedente relativo a los inicios de la biblioteca pública en Argentina:

Los revolucionarios de Mayo, fundaron una biblioteca de gestión gubernativa, es decir, en esa instancia histórica en particular, una creación regulada por un potro-Estado aún inexistente, un Gobierno Provincial, que veía a esa institución dentro de un marco de política cultural revolucionaria, en una estrecha y dinámica relación entre Biblioteca y Revolución. (Parada, 2012, p. 141) ${ }^{2}$.

De modo que la fundación de la primera biblioteca pública en las coordenadas geopolíticas de la ciudad de Buenos Aires se entreteje con intentos tantos gubernativos como revolucionarios. Se trata de reconocer, bajo este rubro, el papel relevante que desempeñan los gobiernos revolucionarios para consolidar sus proyectos culturales, mismos que les permitan afianzar los logros alcanzados en la gestación y el desarrollo para la conquista del poder estatal.

\section{EL FACTOR POLÍTICO CIUDADANO DE LA BIBLIOTECA PÚBLICA.}

El factor gubernamental, como uno de los enfoques respecto a la estrecha relación que se percibe entre «bibliotecas públicas y política», se vincula y complementa con el factor ciudadano. Estas instituciones, como un servicio de bien común de primer orden (García y Sutherland, 2011, p. 14), pueden ayudar a potenciar el papel de las y los ciudadanos, sin los cuales resulta difícil hacer realidad la democracia en sus tres importantes dimensiones, esto es, como forma: 1] de Estado, 2] de gobierno y 3] de vida. Y sin el conjunto ciudadano democrático, asimismo, es imposible forjar y sustentar el carácter republicano en torno a esta forma política tridimensional que se entreteje cotidianamente. Por esto, en los escenarios políticos de la democracia y de la república se originan las bibliotecas públicas, tanto en la antigüedad y como en la modernidad.

El componente ciudadano de la biblioteca pública está o debe de estar vinculado, teórica y prácticamente, con la causa democrática tanto del Estado como de la sociedad, así como con el valor democrático de esta institución social que debe gestionar servicios bibliotecarios para todos los grupos que conforman la sociedad. Se trata, en suma, de reconocer la capacidad política en torno a ese tipo de centro bibliotecario. Es decir, formular "[...] la dimensión democrática de la biblioteca pública, significa analizar y estudiar una vertiente referente a la dimensión política de esa institución bibliotecaria"; es dilucidar "una relación bibliotecológico-política concreta, esto es, biblioteca pública y democracia en un proceso que apunte hacia la construcción de mujeres y hombres activos, bajo la égida de su condición de ciudadanos" (Meneses, 2008, p. 94). En este sentido, la naturaleza de la biblioteca que nos ocupa se relaciona con asuntos de la ciudadanía y la democracia, tópicos políticos por antonomasia. Con base en esta percepción, es significativo considerar el punto de vista que expresa: "La biblioteca pública es una institución esencial para la democracia", por lo que este mismo autor afirma: "La relación entre biblioteca y cultura cívica debe ser fortalecida" (López, 2008, p. 68). Como deben ser reconocidas las categorías de servicio público, biblioteca pública, lectura pública y educación pública en la estructura político-social de la ciudadanía. Profundicemos al respecto.

Es en estos cuadrantes políticos, como observamos alrededor del mundo y en los diversos ejes de tiempo y espacio, en los que ellas amplían su radio de acción en materia de colecciones y servicios. En este sentido, el personal bibliotecario, profesional y auxiliar, de esas instituciones bibliotecarias está hoy en día convocado y comprometido social y políticamente a estimular la construcción de ciudadanía. Como afirma Berkerman: "La política que practican las bibliotecas públicas es una consecuencia tanto de lo que son como de lo que esperan lograr" (1996, p. 2). De lo que son como instituciones políticas en el entramado de la estructura política del Estado y de lo que esperan alcanzar como instituciones públicas en el marco del proceso político de los gobiernos democráticos y republicanos.

\footnotetext{
${ }^{2}$ Nota del editor: en el original de Parada el autor escribe en cursiva: ..gestión gubernativa....política cultural revolucionaria. Aquí se escribe normal por usar la revista la letra cursiva en los párrafos de obras citadas.
} 
Como se aprecia en la literatura especializada, el factor político/gubernamental de la biblioteca pública converge en el factor político/ciudadano de esta institución de servicio público. Estado y gobierno, democracia y república son los principales elementos que confluyen en la estructura política en que nacen, crecen y evolucionan las bibliotecas públicas para servir al conjunto de ciudadanos. Sujetos con derechos políticos y deberes cívicos. Derechos y deberes que demandan educación, información y conocimiento. Pero en otros trances de la historia, estos espacios bibliotecarios han tenido que convertirse en «bibliotecas políticas» no al servicio público de la ciudadanía sino al servicio gubernamental del Estado. Transfiguradas en bibliotecas públicas políticas en el sentido más amplio del concepto para sujetarse a demandas de adoctrinamiento con el objetivo de formar una población irreflexiva y chauvinista, tal como sucedió en tiempos de la Alemania Nazi (Stieg, 1992, p. 21).

Se piensa que es inevitable la participación de la biblioteca en el plano político porque la ubicación de este centro bibliotecario, dentro de la estructura gubernamental, está ligado con el proceso político inherente, insistamos, a la asignación del presupuesto requerido que el gobierno, brazo ejecutor del Estado, debe asignar para el eficaz funcionamiento del servicio de biblioteca pública (Beckerman, 1996, p. 25). Pero la participación de esta institución cultural no se reduce a este acotado escenario gubernamental, por el contrario, la participación política de ella alcanza la estructura social en que se mueven las personas en su condición de ciudadanos. En razón de esto se asevera:

La biblioteca pública tiene un papel que desempeñar en el desarrollo de una democracia informada y educada.

Los miembros de la profesión creen que el servicio de biblioteca pública sirve para extender la ciudadanía mediante el acceso a las ideas, a la información y a las obras de la imaginación que hacen posible la participación en la vida social y comunitaria. (Usherwood, 1996, p. 190).

Es por esto que en el entrecruce de la democracia con la ciudadanía se estima que “... la biblioteca debería ser una prioridad en manos de un político o de un ayuntamiento que se dirija a sus ciudadanos" (Jornadas Biblioteca Pública y Políticas Culturales, 1997. p. 103). Si la democracia es una forma en donde cohabitan multiplicidad de valores culturales, cívicos, morales y otros; y si la república es una forma justa de gobierno porque está regida por políticas públicas sustentadas por la legislación creada en sus diferentes niveles orgánicos, estructurales y territoriales, entonces el espíritu político del Estado democrático-republicano se puede proyectar a través de la práctica que implica hacer realidad, entre el pueblo, el derecho a leer, consecuentemente, el derecho de contar con espacios para la práctica de la lectura pública. Así, en el marco de una política bibliotecaria, con tendencia a ofrecer servicios de biblioteca pública que requieren las personas en su calidad de ciudadanos, se deben seguir contemplando apreciaciones históricopolíticas como la siguiente:

Todas las naciones cultas han promulgado a esta fecha su ley de Bibliotecas públicas, creando un impuesto especial para su sostenimiento, o bien obligando a los municipios a dedicarles una parte proporcional de sus ingresos. Los Gobiernos han coincidido en apreciar que la lectura pública reúne todos los caracteres jurídicos necesarios para considerarse en derecho como un servicio público primordial para la vida del Estado. (Lasso de la Vega, 1934, p. 9-10).

Palabras que corresponden al período político de la historia de España conocido como la Segunda República. Tiempo en que el servicio de biblioteca pública floreció en aquel país; etapa en la que el libro y la lectura figuraron como componentes importantes de la política cultural de un gobierno que se preocupó y ocupó por acercar al pueblo acervos y servicios bibliotecarios de carácter público. Observamos así que este tipo de biblioteca se convirtió, en ese contexto, en una necesidad política tanto para el pueblo como para el gobierno, es decir, para la organización de un sistema republicano como forma de Estado. En la esfera de la política del libro durante aquella Segunda República se valora:

\footnotetext{
El nuevo Estado con la generalización de la lectura pública «republicana» pretendía asociar las bibliotecas con la democracia. Para que un ciudadano pudiera ejercer sus derechos y deberes libremente en un estado democrático debía tener a su disposición los medios necesarios para instruirse e informarse acerca del mundo que le rodeaba. La biblioteca fue un agente de socialización politica del régimen en un intento de republicanizar a los ciudadanos del país, ya que puso a disposición de éstos numerosas publicaciones para elevar su formación intelectual y profesional, así como para facilitar el ejercicio de los nuevos derechos políticos adquiridos. Al mismo tiempo, muchos de estos libros contribuyeron a la difusión de los valores republicanos y democráticos. (Martínez, 2003, p. 24-25).
}

Podemos afirmar así que la historia de la biblioteca pública, en las diversas coordenadas de tiempo y espacio, puede ser una forma de acercarnos al conocimiento que nos permita saber el papel que ésta ha desempeñado para ayudar a construir una ciudadanía capaz de actuar en la esfera del Estado democrático y republicano. Punto de vista que podemos articular con el nexo «biblioteca pública, lectura pública y comportamiento político» en tiempos de elecciones. Tema sobre el que reflexionamos a continuación. 


\section{EL FACTOR POLÍTICO ELECTORAL DE LA BIBLIOTECA PÚBLICA.}

El paradigma político de la biblioteca pública comprende también una relación poco usual: «bibliotecas públicas y partidos políticos». Esta relación general no se reduce solamente a las opiniones que los políticos de los diversos partidos emiten en relación con el servicio de la biblioteca pública (Usherwood, 1993; Black, 1996, p. 53; Smith and Usherwood, 2003) en determinadas temporadas. Tampoco se refiere únicamente al nexo «bibliotecas públicas, partidos políticos y elecciones», esto es, respecto a las políticas bibliotecarias que esgrimen como promesas los candidatos de los institutos políticos durante los procesos electorales generales y que han sido analizadas en España (Sánchez, 1994). Perspectiva que más tarde, en una emblemática revista española, se ampliaría mediante la nota «Los partidos políticos y la biblioteca» y en la que se consideró importante "conocer cuál es la concepción bibliotecaria de cada uno de los partidos políticos" (Educación y Biblioteca, 1996, p. 7) en tiempos de elecciones. Asunto que diez años después se volvería a tratar al concluirse en el escrito de un seminario hispano-mexicano: "Debemos exigirles a los partidos políticos que reflejen en sus programas electorales, su dedicación a los temas derecho/deber a la información. Debemos hacerles saber que nuestro voto estará condicionado en el futuro al cumplimiento de sus promesas" (Ros García, 2006, p. 51). La problemática en cuanto a «bibliotecas, partidos y políticos» no era desconocida para el caso la Gran Bretaña:

El impacto de la política de los partidos formales sobre la cuestión de la biblioteca pública no es un desarrollo completamente nuevo. En el siglo XIX los liberales apoyaron notablemente el movimiento de las bibliotecas públicas. El promotor de biblioteca y editor Thomas Greenwood estuvo activo en la politica liberal. Al igual que el benefactor de bibliotecas John Passmore Edwards, quien se desempeñó como miembro del Glastonian Parlament entre 1880 y 1885. El liberal John Lubbock (desde 1900 Lord Averbury) se hizo cargo de William Ewart como el principal defensor parlamentario del movimiento de la biblioteca pública. (Black, 1996, p. 54).

Pero el problema aludido tiene otra dimensión política no menos relevante: «bibliotecas públicas, partidos políticos e información electoral». Este vínculo sugiere que estos centros bibliotecarios pueden participar activamente, como en algunos países sucede, en los procesos electorales concernientes a la renovación periódica de los poderes públicos de elección popular, es decir, de los poderes Ejecutivo y Legislativo. De lo que se trata es que los bibliotecarios públicos no continúen heredando la abstención política en torno a los actos que documentan los partidos políticos y sigan ellos, en consecuencia, omitiendo su responsabilidad de ilustrar a la ciudadanía en materia de información electoral a través de los servicios que gestionan.

Así, a pesar de que las bibliotecas públicas han desempeñado un papel bastante pasivo durante tiempos de procesos políticos, esto es, cuando la ciudadanía tiene el derecho y el deber de elegir a sus representantes populares, se ha reconocido la posibilidad de poder revertir esta situación. Con razón se afirma que: "Las bibliotecas de todos los tipos -públicas, escolares y académicas- pueden desempeñar un papel vital en el proceso electoral” (Link, 1984, p. 1597). Consecuentemente, estos espacios de lectura pública pueden ser considerados para actuar como dispositivos de «información política» en tiempos de comicios. Pero, en concreto, ¿qué podrían hacer las bibliotecas públicas durante temporadas de elecciones?

Si consideramos que la información política que difunden los medios de comunicación masiva a menudo no satisfacen las exigencias ciudadanas en cuanto a «información electoral» se refiere, entonces los centros bibliotecarios, a disposición de toda la población, pueden contribuir en mantener mejor informada a la sociedad en torno a los acontecimientos políticos que exigen lectura política. Sabemos que las notas informativas durante una campaña para elecciones presidenciales, por ejemplo, no son suficientes para informar a la ciudadanía con derecho a sufragar. La cobertura del proceso electoral en radio y televisión para la difusión de promocionales de partidos políticos y autoridades electorales, desde el inicio de las precampañas de los candidatos hasta el día en que se celebra la jornada electoral, puede ser amplia pero esa información comúnmente es exigua o incompleta porque las emisoras solamente están obligadas a transmitir la información que al respecto aprueba la autoridad electoral o la que conviene a los candidatos y, por ende, a los partidos en contienda. El impacto social de la difusión de este recurso durante los procesos político-electorales y en un contexto pluripartidista se infiere al afirmar que:

En las sociedades modernas, cada persona tiene necesidad de conocer lo que sucede en su entorno para poder actuar en libertad. La verdadera libertad sólo se da en el individuo cuando dispone de información que le permita elegir entre varias opciones. De esta manera, cuando la información es incompleta, insuficiente, tergiversada o inexistente, el individuo sigue teniendo esa capacidad de elegir, pero de forma parcial y limitada. (Sosa, 1998, p. 18).

Desde esta perspectiva, la ciudadanía requiere saber acerca del obrar político, positivo y negativo; así como las especificidades de los proyectos de nación y las agendas de trabajo de las y los candidatos presidenciales. Las 
bibliotecas públicas en este sentido tienen la posibilidad de incluir en sus acervos la «bibliografía política» y la documentación político-electoral de los partidos contendientes y la de sus candidatos, además la información emitida por los órganos competentes sobre la normatividad del proceso electoral. No se trata de que las bibliotecas públicas se inclinen por un determinado partido político, sino de que estos centros ofrezcan la información político-partidista de todos los institutos políticos que cubren el escenario de las contiendas electorales.

En esta contextura, la información electoral es una categoría específica de la información política, cuadrante en el que las bibliotecas públicas pueden sumarse al derecho político, jurídico y electoral de acceso a este género de información. Lo que se trata es que el conocimiento y las ideas complementen la publicidad y la propaganda políticas sobre asuntos de campañas electorales. Los servicios bibliotecarios destinados a toda la población así podrían apoyar la equidad en materia electoral, la cual "tiene como misión la de compensar las desventajas contingentes en que se encuentran algunos partidos políticos en dirección a la igualdad de aquéllos que posean un mayor capital político y representativo en los órganos de gobierno" (Quiñones, 2002, p. 55).

Es decir, si las bibliotecas públicas desempeñan la función de información y este recurso es necesario durante los procesos electorales en el marco de un Estado democrático; y si estas instituciones son constructoras de ciudadanía, entonces ellas pueden y deben contribuir con su grano de arena informando a la comunidad acerca de los partidos, los candidatos y sus agendas y proyectos políticos. Para tal efecto se estima que la literatura de campaña que publican los diversos partidos políticos es la materia prima esencial en la relación que existe entre «bibliotecas, información y elecciones». De modo que el "primer paso en la obtención de información sobre las elecciones es identificar quién está produciendo esa información" (Link, 1984, p. 1598) durante las diferentes cuatro etapas que comprende el proceso electoral, a saber: 1] la campaña electoral, 2] la jornada electoral, 3] los resultados y la validez de las elecciones y 4] el dictamen y las declaraciones de validez de los candidatos electos. Todo esto, en concordancia con los actos regulados y las actividades autorizadas por la constitución política, la legislación y la reglamentación electoral reconocidas por las autoridades, los partidos políticos y los ciudadanos. En cuanto a la información generada por estos partidos se considera que:

La mayoría de los partidos, especialmente los más pequeños, están dispuestos a enviar una gran variedad de materiales de forma gratuita y también están dispuestos a agregar el nombre de su biblioteca a su lista de correo regular. Las cartas recordativas cada mes o dos pudieran ser útiles si encuentra que usted no está recibiendo los materiales. La mayoría de los partidos disponen de una publicación periódica, un boletín, revista o periódico que puede proporcionar al día la información sobre las actividades de los partidos y candidatos. Por último, los partidos políticos también son el contacto clave para los candidatos individuales que funcionan con el apoyo del partido. (Link, 1984, p. 1598-1599).

La información electoral no se limita a las campañas de promoción del voto, es decir, no se circunscribe a la «propaganda partidista». También la «propaganda gubernamental» produce una gran cantidad de documentación. Esto equivale a que las campañas de información no corren a cuenta solamente de los partidos, sino también de las autoridades electorales. Información documentada que puede tener cabida en las bibliotecas públicas para mantener, en efecto, una ciudadanía informada en relación con mecanismos aprobados respecto a los procesos electorales que a ella le incumben. Parece entonces que estas bibliotecas deben y pueden contribuir de manera importante a la promoción de la participación ciudadana para el ejercicio del derecho al sufragio que invocan las autoridades electorales, los partidos políticos y sus candidatos. El conocimiento por parte de la ciudadanía en torno a los candidatos y a los institutos políticos que los postulan es relevante porque como afirma Carbonell:

Un candidato o un partido político no tiene solamente un interés general en que sus mensajes y su ideología se conozcan, sino que dependen de ello para tener éxito electoral. La conquista del voto depende, en primer lugar, de que el ciudadano sepa que un partido político existe, y luego de que conozca sus planes o propuestas.

Sin visibilidad en el espacio público un partido político está condenado al ostracismo y, en definitiva, al fracaso electoral (2008, p. 40).

La información sobre los estatutos, la declaración de principios, los programas de acción, los antecedentes de sus líderes, los reglamentos, el financiamiento público, los convenios con la coalición, etcétera, puede ser de interés no solamente para los órganos de vigilancia y militantes de los partidos, sino también para los simpatizantes de los mismos y la sociedad en general. La información pública de estas organizaciones podría ser componente importante de los acervos y servicios de las bibliotecas públicas, recurso esencial del derecho a la información pública en los Estados democráticos. Estos espacios públicos de socialización de recursos bibliográficos pueden ser, por ende, una alternativa cultural de las estrategias de comunicación política tanto de las autoridades electorales como partidistas. Naturalmente es necesario que los sistemas de bibliotecas públicas, en sus diferentes niveles geopolíticos, respeten los límites y alcances que marca el ordenamiento jurídico del acceso a la información pública en materia electoral (Nava, 2009) de 
cada país. Lo cierto es que, como asevera Link: "Las mentes creativas de los bibliotecarios pueden encontrar muchas maneras para informar al público sobre la información que determinamos como importante o útil para la toma de decisiones políticas" (1984, p. 1600). Y el tema del proceso electoral, vinculado estrechamente con el fenómeno de la información electoral, es un asunto relevante que impacta en todos los niveles de la sociedad y no solamente de las esferas gubernamentales y partidistas.

En materia de «cultura política» es importante la «cultura electoral» de la sociedad, tanto en tiempos de comicios como en otros periodos en que la participación ciudadana es fundamental para forjar el Estado de democracia. Así, entre las actividades que los sistemas de bibliotecas públicas pueden llevar a cabo en tiempos electorales, entre otros periodos, podemos destacar las siguientes:

- Programar conferencias y discusiones acerca de los institutos políticos reconocidos por el sistema de gobierno, el sistema electoral y el sistema de partidos políticos, como parte esencial de los servicios de extensión bibliotecaria para niños, jóvenes y adultos.

- Desarrollar y organizar acervos, impresos y digitales, que garanticen el acceso a la información políticoelectoral que la ciudadanía requiere para participar en los procesos de toma de decisiones políticas en torno a esa triada de sistemas estructurales que conforman el orden político-institucional del Estado.

- Coordinar trabajo con las bibliotecas especializadas en materia de información político-electoral, particularmente con aquellas que dependen de esos tres sistemas políticos.

Todo esto con la visión de que estas instituciones bibliotecarias, dedicadas a servir al pueblo, contribuyan a enriquecer la cultura política en general y la cultura electoral en particular de la sociedad acerca de ese sistema político que configura el Estado democrático; así como para colaborar en la optimización de la gobernabilidad, la participación y la representación entre esa trilogía de sistemas que distingue Nohlen (1999). Esta perspectiva no es una ilusión, es un paradigma efectivo que al relacionar «elecciones y política», varias bibliotecas públicas de algunos países (Estados Unidos, Canadá, Singapur, y otros) practican al considerar entre sus responsabilidades primordiales el trabajo de difundir, por ejemplo, los actos de campaña de los candidatos de las diferentes fuerzas políticas. Considerando para tal efecto un nivel de equidad para todos ellos.

\section{EL FACTOR POLÍTICO REVOLUCIONARIO DE LA BIBLIOTECA PÚBLICA.}

El concepto de revolución en el campo de la ciencia política no solamente significa un cambio de gobierno, sino una regeneración de la estructura político-social-económica del Estado (Pasquino, 1997, p. 1412). Las revoluciones no solo son luchas políticas violentas para provocar cambios en el equilibrio de los poderes del Estado (Walt, 1992, p. 321), sino que también suelen ser los momentos propicios para pensar y definir nuevas concepciones que permitan plantear nuevos valores y principios; para diseñar y avanzar novedosos proyectos con la finalidad de proporcionar más y mejores oportunidades. Los planes para construir nuevos sistemas bibliotecarios no se han mantenido al margen de las políticas revolucionarias del dúo político gobierno-pueblo.

A lo largo de sus cuatro etapas: gestación, desarrollo, triunfo y consolidación, una revolución necesita de libros y bibliotecas para practicar tanto la lectura informativa como la lectura formativa, sin menoscabo de la lectura recreativa. Recursos y procesos intelectuales que le han otorgado a todo movimiento revolucionario moderno tanto un sentido táctico como estratégico, pues para cambiar un caduco orden social y construir uno nuevo se necesitan de escritos y documentos, de información y conocimiento, de análisis y estudio, de ideas y debate. En suma, se requieren de centros bibliotecarios con colecciones bibliográficas organizadas no solamente a disposición de los intelectuales revolucionarios, sino también se necesitan bibliotecas para "informar al pueblo y formar al pueblo" (Sosa, 2011, p. 11). Por esto, en ocasiones se conciben metafóricamente a "las bibliotecas como hijas y herederas de la Revolución" (Parada, 2012, p. 155), peculiarmente las bibliotecas públicas puesto que ellas están al servicio del pueblo. Esto nos lleva a configurar la elocuente unión entre «biblioteca, pueblo y revolución», en la que resalta la figura del servicio de biblioteca pública.

Así que la relación entre «biblioteca pública y revolución» no ha pasado inadvertida en la literatura históricobibliotecológica. Por ejemplo, en torno a la revolución cubana este fenómeno se ilustra con el libro Biblioteca pública y revolución: su desarrollo de 1959 a 1989 (Viciedo, 2009). En el contexto argentino cabe mencionar la obra Los orígenes de la Biblioteca Pública de Buenos Aires: antecedentes, prácticas, gestión y pensamiento bibliotecario durante la Revolución de Mayo (1810-1826) (Parada, 2009). Este mismo autor en otro de sus escritos, en relación con la biblioteca tradicional versus la biblioteca revolucionaria, sintetiza el hecho histórico de ese centro bibliotecario de uso público en tres manifestaciones, a saber: "el surgimiento de la biblioteca pública como un instrumento del Gobierno para la instrucción de los ciudadanos, la utilización de esta institución como un elemento político y revolucionario, y la participación de la ciudadanía en su gestión y desarrollo" (Parada, 2012, p. 173). Antecedente 
histórico que nos conduce a pensar en la estrecha relación política que existe entre «bibliotecas, ciudadanía y revolución». En efecto, con base en este razonamiento Parada asevera: "Los principios bibliotecarios de la Revolución de Mayo se agrupan en una tríada fuertemente articulada: pensamiento revolucionario, manifestación política e intervención ciudadana" (2012, p. 185. Las cursivas son del autor).

De acuerdo con esta contextura, la unidad «biblioteca y revolución» es otro componente del paradigma político de la biblioteca pública y de otros tipos de bibliotecas, como las de carácter humanístico, porque esta liga conceptual implica, desde una perspectiva histórica, cambios sociales, políticos, ideológicos, educativos y culturales de toda índole. Este nexo conceptual evidencia asimismo complejos movimientos de los pueblos que tienden a generar transformaciones radicales (Meneses, 1994, p. 29-31). Cambios incluso en relación con la educación en bibliotecología, como sucedió después del triunfo de las revoluciones china (Lin, 1998, p. 165), cubana (Viciedo, 2009, p. 70-71) y nicaragüense (Bloch y Acevedo, 1988, p. 170). En esos tres contextos hubo la necesidad de formar y capacitar, aún con escasos recursos, a los cuadros de bibliotecarios profesionales y auxiliares que habrían de hacerse cargo de los nuevos sistemas de bibliotecas públicas erigidos por los gobiernos revolucionarios. Toda esa labor educativa fue de acuerdo con los proyectos de desarrollo apegados a lo que apropiadamente Parada llama «política cultural revolucionaria» (2012, p. 141). Consideremos, para esclarecer mejor este asunto, algunos antecedentes sobre el factor que nos ocupa respecto a esas tres revoluciones.

En relación con China se sabe que

La importancia de las bibliotecas en el movimiento de educación era tan obvia que el gobierno pronto lanzó su vasto programa de ampliación de la biblioteca. [...] En unos diez años, el número total de bibliotecas en China se multiplicó extraordinariamente desde menos de mil a más de 300.000. p. 17.

Desde 1949, no sólo fue un gran aumento el número de bibliotecas, sino que la naturaleza de la biblioteca, sus funciones y servicios, así como la naturaleza de la propia biblioteconomía también pasó por cambios radicales. Las bibliotecas se definieron como instituciones culturales para educar a las personas en el patriotismo y el socialismo, y una de sus funciones fue la de utilizar sus recursos para hacer propaganda marxista-leninista. Los trabajadores de la biblioteca aumentaron enormemente en número, tuvieron que ser reeducados en la filosofía política y la formación profesional para convertirse en un ejército "rojo y experto" para operar las bibliotecas en la nueva sociedad socialista. (Lin, 1983, p. 18-19).

\section{En el caso de Cuba}

Lo primero que se puso de manifiesto fue una nueva concepción profesional del trabajo bibliotecario, que se generalizó en toda la Isla, imbuida del espíritu y las transformaciones revolucionarias. El primer reconocimiento al status social del bibliotecario se produjo con la Ley no. 684 del Gobierno revolucionario que normó el trabajo bibliotecario para abrirle paso a esta nueva concepción.

La reforma general de la enseñanza cubana de 1961 resultó un factor decisivo para la creación de la Red de Bibliotecas Públicas del Consejo Nacional de Cultura [...] (Viciedo, 2009, p. 69).

\section{Respecto a Nicaragua}

El Ministerio de Cultura fue creado el 20 de julio de 1979, el día después de que las tropas sandinistas entraron triunfalmente en Managua. Menos de un año después, el Ministerio estableció la Administración General de Bibliotecas y Archivos. La Biblioteca Nacional, el Archivo Nacional, las bibliotecas públicas, y el Centro Nacional de Catalogación se colocaron bajo su cargo (Bloch y Acevedo, 1988, p. 170).

A partir del triunfo de las revoluciones en esos países se distingue: 1] El reconocimiento en torno a la importancia del papel que las bibliotecas en general y las bibliotecas públicas en particular podían y debían desempeñar en relación con la formación e información del pueblo; 2] El desarrollo de un nuevo concepto respecto al funcionamiento social de las bibliotecas para respaldar las tareas de reconstrucción nacional, 3] El instituir un nuevo sistema de bibliotecas como parte integral de la nueva estructura pública con miras a la reconstrucción social y política del Estado; y 4] La propagación, a través de los servicios bibliotecarios, de las ideas políticas y sociales que abanderaron aquellos movimientos revolucionarios. Esto muestra la confianza de los revolucionarios en las instituciones bibliotecarias como palancas formidables para ayudar en la transformación de la sociedad. De modo que durante el arduo proceso de una revolución, la praxis de la bibliotecología en general y de la bibliotecología pública en particular, se va configurando con base en las políticas que proyecta el nuevo gobierno, mismas que dan forma y contenido a la revolución cultural. 
El servicio de biblioteca pública en los movimientos revolucionarios, principalmente durante sus fases de triunfo y consolidación, cobra realidad política mediante la acción de los líderes que aspiran a construir espacios de libertad pública para leer. En el contexto de una lucha revolucionaria, reconocemos que la biblioteca adquiere una dimensión política como expresión derivada del orden político dentro de un proceso radical que apunta, como sugieren los teóricos de la revolución, a producir profundos cambios sociales, políticos y económicos (Tanter y Midlarsky, 1967, p. 265). Entorno en el que se va configurando la conversión del súbdito en ciudadano (Sosa, 2011, p. 4). La cultura bibliográfica en general y la cultura bibliotecaria pública en particular han formado parte relevante durante la trama de importantes revoluciones, como las acontecidas en Francia, Rusia, México, China, Cuba, Nicaragua y otros países. Estos movimientos progresistas así han estado vinculados con la libertad de leer, la que se configura durante la instauración de contextos republicanos como una libertad política para elevar el nivel de ilustración del pueblo, con la finalidad que éste logre participar en los asuntos comunes; para que él pueda interesarse en los asuntos públicos. Estos espacios bibliotecarios tienen el brío de construir el componente ciudadano pues se reconoce en términos generales que:

Las bibliotecas tienen el poder para producir (en palabras de $S R$ Ranganathan) 'la felicidad material, la alegría mental y el deleite espiritual'; son 'instituciones sociales encargadas de la obligación de proporcionar los medios para la auto-educación perpetua de todos y cada uno', y entonces contribuir a la circulación de ideas, al aprovechamiento del ocio, a las exigencias de la democracia, a la propagación de la alfabetización y al éxito de las empresas comerciales e industriales. Expresado de manera más radical, es cierto decir que las bibliotecas son instrumentos poderosos del cambio social y político. Expresado incluso más radicalmente, las bibliotecas existen para el bien de la libertad de pensamiento. (Thompson, 1974, p. 9-10).

En esta contextura política, las bibliotecas públicas son tema tanto de aspiración republicana como de espíritu revolucionario; son materia tanto de proyecto ciudadano como de propósito democrático. Con base en esta percepción se ha llegado a valorar en ocasiones que "la biblioteca pública ha sido y se utiliza como un instrumento político para el cambio político y social" (Usherwood, 1996, p. 191). Aunque a veces también se ha usado como dispositivo político para el estancamiento o retroceso del Estado y de la sociedad, es decir, para favorecer el status quo de gobiernos nefandos. Las bibliotecas públicas en las dictaduras militares de América Latina durante el siglo XX es un ejemplo en este sentido. Razón por la que se infiere:

Las bibliotecas públicas son un producto de la historia. Al igual que otras instituciones públicas, las bibliotecas públicas funcionan en el contexto de diferentes sistemas politicos. Debido a esto, hay diferentes puntos de vista en cuanto a su propósito político. Las bibliotecas públicas en todo el mundo son financiadas por los gobiernos de alguna descripción. La existencia de estas bibliotecas se encuentra en un entorno politico que podría no ser del todo favorable para ellas. (Smith and Usherwood, 2003, p. 76).

Hay periodos políticos que, en efecto, las bibliotecas están bajo ataque constante. Abundan los actos de censura que practican contra ellas los diversos aparatos del Estado y los grupos conservadores de la sociedad en ciertas atmósferas de represión e intolerancia. Esto es muestra que el poder de la biblioteca y el poder de la información documental se manifiestan paralelamente porque el binomio biblioteca-información es tanto un instrumento intelectual a disposición de la clase socialmente dominante como un recurso liberador disponible para la clase socialmente dominada. Es en este cuadrante dialéctico y antagónico que las bibliotecas públicas se distinguen en determinadas épocas también como "instrumentos de cambio social y político", puesto que como "guardianes de la libertad de pensamiento, son bastiones de la libertad" (Thompson, 1974, p. 110); y son también baluartes de la igualdad y la justicia en el seno de la sociedad.

Dicho de otra manera, en los Estados capitalistas las bibliotecas públicas coadyuvan ordinariamente al control social, puesto que su objetivo político general, acordado desde las esferas de la política cultural del Estado, es controlar el acceso a la información y, por ende, los hábitos de lectura del pueblo para así asegurar que tenga éste las habilidades necesarias que apunten a perpetuar el sistema social capitalista. Desde esta óptica política, esas instituciones son herramientas culturales de información bibliográfica para reproducir la economía capitalista, es decir, para beneficiar el stablishment constituido por el grupo dominante que detenta el poder del Estado. Aunque cabe reconocer que esta tendencia preponderante ha logrado, en ciertas épocas prerrevolucionarias y revolucionarias, revertirse a favor de las clases subalternas. En este sentido, esta naturaleza de biblioteca es producto también de la acción política del pueblo lector.

\section{CONCLUSIONES.}

La conexión «bibliotecas y Estado» concierne en sustancia al paradigma político de este tipo de centro bibliotecario; este paradigma responde entonces a lo que el autor denomina como «bibliotecología política». 
En la literatura bibliotecológica el prototipo político de la biblioteca pública comprende especialmente dos relaciones: «política y bibliotecología pública» y «política y bibliotecas públicas». Enfoques y categorías que permiten construir conocimiento en torno a esa rama especializada de la bibliotecología.

El potencial político de la biblioteca pública moderna está expresamente vinculado con el proceso político tanto del Estado como de la sociedad. No obstante que esta institución desde sus orígenes ha estado entrelazada a proyectos políticos, el mundo político de la misma comenzó a concebirse explícitamente a lo largo del siglo XX. La literatura sobre esta temática es un indicio evidente. Asimismo, la biblioteca pública no está al margen de la política y la política no es ajena al desarrollo de esta institución pública. La práctica bibliotecaria es clara señal en este sentido.

De modo que es un mito pensar que las bibliotecas públicas no son instituciones políticas. Con base en esto, se reafirma que la bibliotecología pública es, evidentemente, política. Este enfoque sugiere pensar que las bibliotecas destinadas al pueblo en general, son instituciones políticas porque se hallan, además, en la arena política de la Administración Pública del Estado. Por lo tanto, esta vertiente concerniente a la disciplina del bibliotecólogo se puede relacionar, desde diferentes dimensiones teóricas e históricas, con los fenómenos y objetos de estudio y análisis de la bibliotecología política.

El factor gubernamental infiere que las bibliotecas públicas son: objeto de políticas de equipamiento; materia de políticas de educación pública; argumento de políticas de información; asunto de políticas de recreación cultural; y tema de políticas de bienestar social. Por esto, el servicio de biblioteca pública es un tema relevante de las políticas de gobierno y de Estado. En virtud de la naturaleza de la biblioteca pública, ésta es una institución normada por diferentes ramas del Derecho.

El factor ciudadano de la biblioteca pública, en el marco del paradigma político de esta institución, nos ayuda a reconocer el papel de las y los ciudadanos en el entramado del Estado democrático. Por esto, en los estadios políticos de la democracia y de la república encontramos el origen de las bibliotecas públicas, tanto las antiguas como las modernas. Este factor se evidencia aún más hoy en día porque el personal bibliotecario, profesional y auxiliar, de esas instituciones bibliotecarias está convocado y comprometido social y políticamente a estimular la construcción de ciudadanía. Con base en este razonamiento, la biblioteca pública tiene un papel preponderante que desempeñar en el desarrollo de una democracia informada y educada.

El factor electoral se refiere a la relación «bibliotecas públicas, partidos políticos y elecciones». Nexo que sugiere que estos centros bibliotecarios participan o pueden participar activamente en los procesos electorales referentes a la renovación periódica de los poderes públicos de elección popular. Por lo tanto, estos espacios de lectura pública pueden actuar como dispositivos de «información política» en tiempos de comicios. El supuesto es si a las bibliotecas públicas se les atribuye la función de información y este recurso es esencial durante los procesos electorales en el Estado democrático, entonces ellas pueden contribuir informando a la comunidad acerca de los partidos, los candidatos y sus proyectos políticos. De tal suerte que esta institución contribuye o puede contribuir así a generar cultura política y cultura electoral entre la sociedad.

El factor revolucionario engloba el papel de la biblioteca pública en los diversos movimientos revolucionarios. La realidad política se evidencia mediante la acción de los intelectuales revolucionarios que aspiran a construir espacios de libertad pública para leer. De tal modo, esta biblioteca ha formado parte relevante de la trama de grandes revoluciones acontecidas alrededor del mundo. Esto ha sido así porque los movimientos que han buscado cambios radicales y totales de la sociedad, han estado vinculados con la libertad de leer y con relevantes campañas contra el analfabetismo. La consigna revolucionaria de esos intelectuales a través de la historia ha sido «los libros y las bibliotecas son para todos».

\section{BIBLIOGRAFÍA.}

ALMEIDA JÚNIOR, O.F. Participação política do bibliotecário ou por uma biblioteconomia guerrilheira. En Sociedade e biblioteconomia. São Paulo: Editora Polis: Associação Paulista de Bibliotecários, 1997, p. 89-93.

ANDRADE SÁNCHEZ, E. Servicios públicos municipales. En Derecho municipal. México: Oxford University Press, 2006, p. 262-298.

BERELSON, B. The public library, book reading, and political behavior. The Library Quartely. 1945, vol. 15, $\mathrm{n}^{\circ} 4, \mathrm{p}$. 281-299.

BERGEN, D. The policy approach to public librarianship. Public Libraries, 1985, vol. 24, nº 2, p. 55-57. 
BERKERMAN, E. Politics and the American public library: creating political support for library goals. Landhm, Md.: The Scarecrow, 1996.

BIRDSALL, W.F. The political persuasion of librarianship. Library Journal, 1988a, vol. 113, n 10, p. 75-79.

BIRDSALL, W.F. Public libraries and political culture. Public Library Quarterly. 1988b, vol. 8, no 3-4, p. 55-65.

BLACK, A. Local politics and national provision. En KINNELL, M. y STURGES, P. (eds.). Continuity and innovation in the public library: the development of a social institution. London: Library Association Publishing, 1996, p. 48-66.

BLANKE, H.T. Librarianship \& political values: neutrality or commitment? Library Journal, 1989, vol. 114, $\mathrm{n}^{\circ} 12$, p. 39-43.

BLOCH, T. y ACEVEDO, A. Library education in revolutionary Nicaragua. Journal of Education for Library and Information Science, 1988, vol. 28, n 3, p. 169-176.

BOBBIO, N. Política. En Diccionario de política l-z. México: Siglo XXI, 1997, p. 1215-1225.

BURTON, J. Theory and politics in public librarianship. Progressive Librarian, 2009, nº 32, p. 21-28.

CARBONELL. M. La libertad de expresión en materia electoral. México: tribunal Electoral del Poder Judicial de la Federación, 2008.

CARRIGAN, D. Politics and the public library. Public Library Quarterly, 1989, vol. 9, n 3, p. 13-22.

DEPALLENS, J. La bibliotecología necesita de una revolución cultural. Revista Interamericana de Bibliotecología, 1987, vol. 10, n 1, p. 7-14.

DOSA, M.L. Libraries in the political scene. Westport: Greenwood Press. 1974.

EDUCACIÓN Y BIBLIOTECA. Los partidos políticos y la biblioteca. Educación y Biblioteca, 1996, año 8, nº 67, p. 7-9, 11-12.

MARTIN, W. Libraries and politics. Librarians for Social Change, 1974-1975, vol. 7, p. 9-10, 12.

GARCEAU, O. The public library in the political process. New York: Columbia University Press, 1949.

GARCÍA, J. y SUTHERLAND, S. Directores de biblioteca pública en la arena politica. Barcelona: Fundación Bertelsmann, 2001.

GARCÍA MARTÍNEZ, A.T. Política bibliotecaria. Convergencia de la política cultura y la política de información. Boletín de la Asociación Andaluza de Bibliotecarios, 2003, vol. 18, n $\mathrm{n}^{\mathrm{T}}$ 71, p. 25-37.

JORNADAS Biblioteca Pública y Políticas Culturales. La biblioteca pública: un compromiso político. Barcelona: Fundación Bertelsmann, 1997.

LASSO DE LA VEGA, J. Política bibliotecaria. Boletín de Bibliotecas y Bibliografía. 1934, vol. I, nº 2, p. 10-15.

LESCIEUR TALAVERA, J.M. El derecho de la política. México: Porrúa, 2000. $3^{\mathrm{a}}$ ed.

LICK, T. Political elections: the library role. Library Journal, 1984, vol. 109, n 14, p. 1597-1601.

LIN, S.C. Education for librarianship in China after the cultural revolution. Journal of Education for Librarianship, 1983, vol. 24, no 1, p. 17-19.

------------. Libraries for politics (1949-1976). En Libraries and librarianship in China. Westport, Connecticut: Greenwood Press, p. 13-17.

----------. Library and information science education. En Libraries and librarianship in China. Westport, Connecticut: Greenwood Press, 1988, p. 163-183.

LÓPEZ LÓPEZ, P. El mito de la neutralidad en biblioteconomía y documentación. Educación y Biblioteca, 2008, año $20, n^{\circ} 166$, p. 62-68.

MARTÍNEZ RUS, A. La política del libro durante la Segunda República: la socialización de la lectura. España: Ediciones Trea, 2003.

MENESES TELLO, F. Análisis bibliotecológico-político: bibliotecas, democracia y ciudadanía. En GIMENO PERELLÓ, J. y LÓPEZ LÓPEZ, P. (coords.). De volcanes llena: biblioteca y compromiso social. Gijón, Asturias: Trea, 2007, p. 393-416.

------. Bibliotecas y democracia: el caso de la biblioteca pública en la construcción de una ciudadanía activa. Anales de Documentación, 2008, n⿳0 11, p. 93-127.

--------. Las bibliotecas humanísticas en los movimientos sociales y políticos de los pueblos. Omnia: Revista de la Coordinación General de Estudios de Posgrado, 1994, año 10, n 28, p. 25-40.

NAVA GOMAR, S.O. El derecho de acceso a la información en material electoral. Sufragio: Revista Especializada en Derecho Electoral, 2009, vol. 3, p. 70-97.

NOHLEN, D. Sistema de Gobierno, Sistema Electoral y Sistema de Partidos Politicos: opciones institucionales a la luz del enfoque histórico-empírico. México: Tribunal Electoral del Poder Judicial de la Federación: Instituto Federal Electoral: Fundación Friedrich Naumann, 1999.

O'KELLY, J. The political role of public libraries. Brighton: John L. Noyce, 1977.

PARADA, A.E. Biblioteca y Revolución. En El dédalo y su ovillo: ensayos sobre la palpitante cultura impresa en la Argentina. Buenos Aires: Instituto de Investigaciones Bibliotecológicas, Facultad de Filosofía y Letras, Universidad de Buenos Aires, 2012, p. 131-169. 
La Revolución, el bicentenario y la Biblioteca Pública. En El dédalo y su ovillo: ensayos sobre la palpitante cultura impresa en la Argentina. Buenos Aires: Instituto de Investigaciones Bibliotecológicas, Facultad de Filosofía y Letras, Universidad de Buenos Aires, 2012, p. 171-188.

----------. Los orígenes de la Biblioteca Pública de Buenos Aires: antecedentes, prácticas, gestión y pensamiento bibliotecario durante la Revolución de Mayo (1810-1826). Buenos Aires: Instituto de Investigaciones Bibliotecológicas, Facultad de Filosofía y Letras, Universidad de Buenos Aires, 2009.

PASQUINO, G. Revolución. En Diccionario de política l-z. México: Siglo XXI, 1997, p. 1412-1423.

QUIÑONES TINOCO, C.S. La equidad en la contienda electoral. México: Universidad Nacional Autónoma de México, 2002.

ROBBINS-CARTER, J. Political science: utility for research in librarianship. Library Trenes, 1984, vol. 32, $\mathrm{n}^{\circ}$ 4, p. 425-439.

ROS GARCÍA, J. Las políticas de información y documentación: su reflejo en los programas de los partidos políticos. En MARTINEZ ARELlANO, F. y CALVA GONZÁLEZ, J.J. (comps.). Memoria del Tercer Seminario HispanoMexicano de investigación en bibliotecología y documentación. Tendencias de la investigación en bibliotecología y documentación en México y España, 29 al 31 de marzo de 2006. México: Universidad Nacional Autónoma de México, 2006, p. 41-51.

SÁNCHEZ SÁNCHEZ, J. Bibliotecas públicas y partidos políticos. Las políticas bibliotecarias en los programas electorales (1977-1993). Boletín de la ANABAD, 1994, Tomo 44, n 2, 1994, p. 123-176. Publicado también en SÁNCHEZ SÁNCHEZ, J. Combates por la biblioteca pública en España: artículos, investigaciones y conferencias (1978-2006). España: Almud, 2006, p. 41-88.

SHAVIT, D. The politics of public librarianship. New York: Greenwood, 1986.

SMITH, K. (ed.). The politics of libraries and librarianship: challenges and realities. Oxford, UK: Chandos Publishing, 2009.

SMITH, K. y USHERWOOD, B. Public library politics: an international perspective. Australian Public Libraries and Information Services, 2003, vol. 16, $\mathrm{n}^{\mathrm{o}}$ 2, p. 76-80.

SOSA ÁlVAREZ, I. La pérdida de la inocencia: las bibliotecas de la Revolución. En RÏOS ORTEGA, J. y RAMÍREZ VELÁZQUEZ, C. (Coords.). Procesos revolucionarios y movimientos culturales. México: Universidad Nacional Autónoma de México, Centro Universitario de Investigaciones Bibliotecológicas, 2011, p. 3-16.

STIEG, M.F. Public libraries in Nazi Germany. Tuscaloosa: The University Alabama Press, 1992.

TANTER, R. y MIDLARSKY, M. A theory revolution. The Journal of Conflict Resolution, 1967, vol. 11, $\mathrm{n}^{\circ} 3$, p. 264-280.

THOMPSON, J. Library power: a new philosophy of librarianship. London: Clive Bingley, 1974.

USHERWOOD, B. Politics and the public library service. Journal of Librarianship and Information Science, 1991, vol. $23, \mathrm{n}^{\mathrm{o}} 2$, p. $75-85$.

-----------. Public library politics: the role of the elected member. London: Library Association Publishing, 1993.

Local politics and the public library service. Journal of Librarianship and Information Science, 1994, vol. 26, no 3, p. 135-140.

----------. Public libraries and political purpose. En KINNELL, M. y STURGES, R.P. (eds.). Continuity and innovation in the public library: the development of a social institution. London: Library Association, 1996, p. 189-209.

VICIEDO VÁLDES, M. Biblioteca pública y revolución: su desarrollo de 1959 a 1989. La Habana, Cuba: Ediciones Extramuros, 2009.

VITZANSKY, W. Libraries and politics - Danish reflections and examples. En SMITH, K. (ed.). The politics of libraries and librarianship: challenges and realities. Oxford, UK: Chandos Publishing, 2009, p. 117-127.

WALT, S.M. Revolution and war. World Politics. 1992, vol. 44, nº 3, p. 321-368.

WHITE, H.S. Public libraries and the political process. En WHITE, H.S. (ed.). Librarians and the awakening from innocence: a collection papers. Boston: MA: G. K. May \& Co., 1989, p. 171-178. 